\title{
Mothers' and fathers' childcare involvement with young children in rural families in Malaysia
}

\begin{abstract}
There is a paucity of data on paternal involvement in childcare in traditional Muslim families in Asia. Using culturalecological models of human development that focus on the developmental niche and hegemonic perspectives on masculinity, mothers' and fathers' levels of childcare involvement with infants were examined in 50 twoparent, lowincome, rural Malay Muslim families residing in peninsular Malaysia. The major goals were to examine gender of parent and gender of child differences in involvement in childcare activities. Mothers and fathers were interviewed separately in their homes regarding the amount of time and levels of involvement in bedtime routines, physical care of, playing with, singing to, feeding, and soothing infants. Groupwise comparisons of parental perceptions revealed a marked genderdifferentiated pattern of involvement: Mothers perceived that they were significantly more involved in bedtime routines, physical care, feeding, playing, soothing, and singing to infants than did fathers. On average fathers estimated that they spent $18 \%$ as much time cleaning infants ( 0.63 versus 3.50 hours), $22 \%$ as much time feeding infants $(0.76$ versus 3.49 ), and $56 \%$ as much time playing with infants (2.77 versus 4.92 hours) relative to mothers. These patterns of involvement suggest that in traditional, rural Malay Muslim families, mothers are the primary caregivers to infants, and contrary to the father as play partner hypothesis, mothers engaged in more play with infants than did fathers. Despite divergent levels of involvement, mothers and fathers were equally as inclined to be involved with their male or female infants. Findings are interpreted in terms of traditional Muslim beliefs about gendered ideologies regarding childcare roles and levels of paternal involvement in groups of fathers in rural and urban Malaysia. The limitations, due in part to gathering data from single informants and the nature of the sample, and the implications of the findings for increasing paternal involvement are noted. (C) 2005 International Union of Psychological Science.
\end{abstract}

